\title{
Study of Waste Plastic Mix Concrete with Plasticizer
}

\author{
Baboo Rai, ${ }^{1}$ S. Tabin Rushad, ${ }^{2}$ Bhavesh Kr, ${ }^{2}$ and S. K. Duggal ${ }^{2}$ \\ ${ }^{1}$ Civil Engineering Department, National Institute of Technology Patna, Patna 800005, India \\ ${ }^{2}$ Civil Engineering Department, Motilal Nehru National Institute of Technology, Allahabad 211004, India
}

Correspondence should be addressed to S. Tabin Rushad, tabinrushad@gmail.com

Received 1 February 2012; Accepted 15 March 2012

Academic Editors: M. Maslehuddin and D. Zeng

Copyright () 2012 Baboo Rai et al. This is an open access article distributed under the Creative Commons Attribution License, which permits unrestricted use, distribution, and reproduction in any medium, provided the original work is properly cited.

\begin{abstract}
The fresh and hardened properties of waste virgin plastic mix concrete have been studied (CUR Report 1991). A number of concrete mixes were prepared in which sand was partially replaced by waste plastic flakes in varying percentages by volume. Waste plastic mix concrete with and without superplasticizer was tested at room temperature. Forty-eight cube samples were moulded for compressive strength tests at three, seven, and twenty-eight days. Eight beams were also cast to study the flexural strength characteristic of waste plastic mix concrete. It was found that the reduction in workability and compressive strength, due to partially replacement of sand by waste plastic, is minimal and can be enhanced by addition of superplasticizer.
\end{abstract}

\section{Introduction}

Disposal of plastic waste in environment is considered to be a big problem due to its very low biodegradability and presence in large quantities. In recent time significant research is underway to study the possibility of disposal of these wastes in mass concrete where strength of concrete may not be major criteria under consideration, such as heavy mass of concreting in PCC in pavements. If plastic wastes can be mixed in the concrete mass in some form, without significant effect on its other properties or slight compromise in strength, we can consume large quantities of plastic waste by mixing it in the concrete mass. Plastic is one component of municipal solid waste (MSW) which is becoming a major research issue for its possible use in concrete especially in selfcompacting concrete and light weight concrete. Although some of these materials can be beneficially incorporated in concrete, both as part of the cementitious binder phase or as aggregates, it is important to realize that not all waste materials are suitable for such use.

Concrete has proved to be an excellent disposal means for fly ash, silica fume, ground granulated blast furnace slag (GGBS), marble powder, and so forth which not only traps the hazardous material but also enhances the properties of concrete. Concrete, as a material, has significantly been benefited from the usage of fly ash, silica fumes, and GGBS.
For a constant workability, the reduction in water demand of concrete due to fly ash is usually between 5 and 15\% when compared with Portland cement only mix. The reduction is large at higher $\mathrm{w} / \mathrm{c}$ ratio [1]. In recent years there has been an increased use of mixing the Portland cement and GGBS components directly in the concrete mixer. An advantage of this procedure is that the proportion of Portland cement and GGBS can be varied at will. The granulated slug can be ground to a fineness of any desired value, but usually, greater than $350 \mathrm{~m}^{3} / \mathrm{kg}$. The presence of GGBS in the mix improves workability and makes the mix more mobile but cohesive [2]. However, the workability of concrete containing GGBS is more sensitive to variations in the water content of the mix than is the case with Portland cement only concrete. Mixes containing GGBS are found to exhibit an early loss of slump. The presence of GGBS in the mix leads to retardation of 30 to $60 \mathrm{~min}$ at normal temperatures [3]. Silica fume has a very high reactivity with calcium hydroxide, and this reactivity permits silica fume as a replacement for a small proportion of Portland cement [4]. Marble powder has higher density and it is assumed that this would improve the segregation resistance of the self-compacting concrete. Corinaldesi et al. [5] mentioned that high fineness of marble powder is proved to be very effective in assuming very good cohesiveness of mortar and concrete. They further showed that marble powder had a very high Blaine's fineness value of 
about $1.5 \mathrm{~m}^{2} / \mathrm{g}$ with $90 \%$ of particles passing through $50 \mu \mathrm{m}$ sieves and $50 \%$ under $7 \mu \mathrm{m}$. According to Gupta et al. [6] the value of segregation index increases with the increase in the amount of marble powder as a replacement of fly ash. Binici et al. [7] found that marble dust concrete had higher compressive strength than that of the corresponding lime stone dust and control concrete with equivalent $\mathrm{w} / \mathrm{c}$ and $\mathrm{mix}$ proportion. Batayneh et al. [8] found that glass containing concrete composites was the most consistent composite than fiberglass within the selected range of 5 and 20\% aggregate substitutes. Rebeiz [9] investigated the strength properties of unreinforced and reinforced polymer concrete using an unsaturated polyester resin based on recycle polyethylene terephthalate (PET) plastic waste. The results showed that the resins based on recycled PET can be used to produce a good quality of precast concrete. Sikalidis et al. [10] investigated the utilization of MSW for the production of mortar. Choi et al. [11] investigated the effects of waste PET bottles aggregate on $\mathrm{p}$, properties of concrete. The waste plastic could reduce the weight by $2-6 \%$ of normal weight concrete. However, the compressive strength was reduced up to $33 \%$ compared to that of normal concrete. Similarly, the results of Batayeneh et al. [8] showed the deterioration of compressive strength with an increase in the proportion plastic content. For the plastic proportion of $20 \%$ of sand, the compressive strength was reduced up to $70 \%$ compared to that of normal concrete. Recently, Marzouk et al. [12] studied the use of consumed plastic bottle waste as sand-substitution aggregate within composite materials for building applications and showed the effects of PET waste on the density and compressive strength of concrete. It was found that the density and compressive strength decreased when the PET aggregates exceeded $50 \%$ by volume of sand. Jo et al. [13] investigated the mechanical properties such as compressive strength and flexural strength of polymer concrete using an unsaturated polyester resin based on recycled PET, which contributes in reducing the cost of the material and saving energy. Pezzi et al. [14] used plastic material particles incorporated as aggregate in concrete and evaluated the chemical, physical, and mechanical properties. The results showed that the addition of polymeric material in fractions $<10 \%$ in volume inside of cement matrix does not imply a significant variation of the concrete mechanical features.

The main objective of this paper is to study the behaviour of M30 grade waste plastic mix concrete with and without superplasticizer.

\section{Experimental Program}

Forty-eight cube specimens and eight beams for M30 grade of concrete with four different volume percentages of plastic $(0 \%, 5 \%, 10 \%, 15 \%)$ with superplasticizer and without superplasticizer were cast as recommended by IS: $10262-$ 1982.

\subsection{Material Properties}

2.1.1. Cement. The cement used in the concrete mix design was ordinary Portland cement (OPC) of grade 43. The
TABLe 1: Physical properties of cement.

\begin{tabular}{lc}
\hline Physical properties & Test results \\
\hline Consistency & 28.5 \\
Initial setting time & $130 \mathrm{~min}$. \\
Final setting time & $360 \mathrm{~min}$. \\
Specific gravity & 2.79 \\
Bulk density of cement & $1500 \mathrm{~kg} / \mathrm{m}^{3}$ \\
\hline
\end{tabular}

TABLE 2: Physical properties of course and fine aggregate.

\begin{tabular}{lcc}
\hline Physical properties & Coarse aggregate (CA) & Fine aggregate (FA) \\
\hline Specific gravity & 2.850 & 2.433 \\
Bulk density & $1600 \mathrm{~kg} / \mathrm{m}^{3}$ & $1700 \mathrm{~kg} / \mathrm{m}^{3}$ \\
Fineness modulus & 4.65 & 2.2 \\
Water absorption & $0.4 \%$ & $0.22 \%$ \\
$\begin{array}{l}\text { Free surface } \\
\text { moisture }\end{array}$ & $\mathrm{Nil}$ & 2.0 \\
$\begin{array}{l}\text { Grading of } \\
\text { aggregate }\end{array}$ & IS: $383-1970$ confirms, & IS: $383-1970$, \\
& $20 \mathrm{~mm}$ and lesser size. & conforms zone III \\
\hline
\end{tabular}

various laboratory tests confirming to IS: $4031-1968 \mathrm{spec}-$ ification was carried out and the physical properties are mentioned in Table 1.

2.1.2. Aggregate. The physical properties of the coarse and fine aggregate as found through laboratory test are given in Table 2.

\subsubsection{Water. Water used conforms IS 3025 (part 22, 23).}

2.1.4. Plastic Pallet as Fine Aggregate. The waste material used in this study was virgin plastic and was used as a partial replacement for fine aggregate. It was obtained from the Central Institute of Plastic Engineering and Technology (CIPET) Hajipur, Bihar, India. The fineness modulus and specific gravity for plastic waste were 3.2 and 0.91 , respectively. A sample of waste plastic is shown in Figure 1.

2.1.5. Superplasticizer. In the present study superplasticizer CONPLAST SP 320 was used to enhance workability as well as compressive strength of waste plastic mix concrete. The specific gravity of CONPLAST SP 320 is 1.02 .

2.2. Concrete Mix Design. The concrete mix design as recommended by IS: 10262-1982 was used to prepare test samples and its details are shown in Table 3. Forty-eight cube specimens and eight beams for M30 grade of concrete with four different volume percentages of plastic pallets $(0 \%$, $5 \%, 10 \%$, and $15 \%$ ) were cast. Six cubes were cast for each percentage of plastic pallets without superplasticizer, and six cubes for each varying percentages of plastic pallets have been casted with superplasticizer CONPLAST SP320. Sizes of cube specimens are $150 \mathrm{~mm} \times 150 \mathrm{~mm} \times 150 \mathrm{~mm}$, and sizes of beams specimens are $750 \mathrm{~mm} \times 150 \mathrm{~mm} \times 150 \mathrm{~mm}$. 
TABle 3: Mix proportion.

\begin{tabular}{cccccccc}
\hline \multirow{2}{*}{ Mix } & \multicolumn{7}{c}{ Material by weight $(\mathrm{Kg})$} \\
& \% plastic & Cement & C A & FA & Waste plastic & w/c ratio & Mix proportion \\
\hline \multirow{3}{*}{ M30 } & 0 & 423 & 1282 & 469.00 & 00.00 & 0.44 & $1: 3.03: 1.110: 0.000$ \\
& 5 & 423 & 1282 & 445.20 & 08.76 & 0.44 & $1: 3.03: 1.052: 0.021$ \\
& 10 & 423 & 1282 & 421.73 & 17.50 & 0.44 & $1: 3.03: 0.997: 0.042$ \\
& 15 & 423 & 1282 & 399.00 & 26.40 & 0.44 & $1: 3.03: 0.943: 0.060$ \\
\hline
\end{tabular}

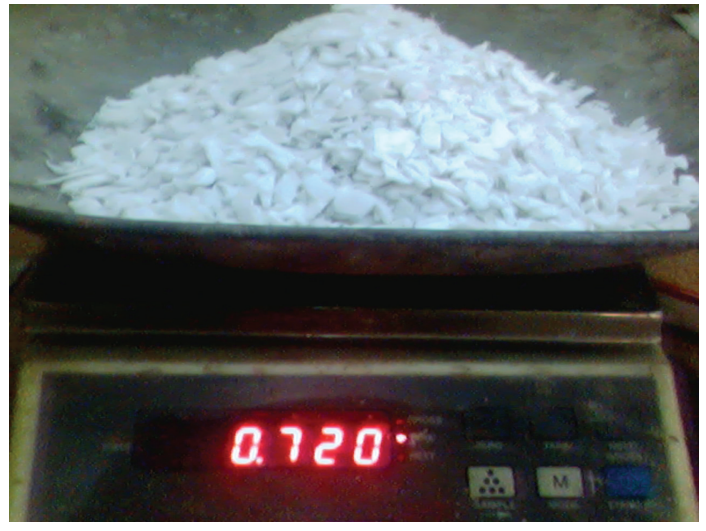

FIGURE 1: Sample of waste plastic.

\section{Results and Discussions}

A comparative study of concrete mix is carried out to find the effect of replacing fine aggregates by plastic pallets, without superplasticizer and with superplasticizer. Properties of waste plastic mix concrete, namely, fresh density, dry density workability, compressive strength, and flexural strength, have been studied and the results are as follows.

3.1. Fresh Density. Figure 2 indicates that the fresh density tends to decrease by $5 \%, 8.7 \%$, and $10.75 \%$ for $5 \%, 10 \%$, and $15 \%$, respectively, below the reference mixtures, that is, $0 \%$. This trend may be attributed to the density of the waste plastic being lower than the sand by $70 \%$, which leads to a reduction in the fresh density.

3.2. Dry Density. The dry density values for waste plastic mix concrete are shown in Figure 3. Dry densities at each curing age tend to decrease with increasing waste plastic ratio in each concrete mixture. It is clear that, at 28 days curing age, the lowest dry density $\left(2225 \mathrm{~kg} / \mathrm{m}^{3}\right)$ exceeds the range of the dry density for structural light weight concrete. The use of waste plastic for each curing age reduced the dry densities of all mixtures with increasing the waste plastic ratio, because the density of plastic is lower than that of sand by $70 \%$.

3.3. Slump. See Figure 4. It was observed here that degree of workability is low when superplasticizer is not mixed in the concrete mixture. When superplasticizer is used, the degree of workability becomes medium till the water plastic content is $10 \%$. The increase in workability is around about 10 to $15 \%$ when superplasticizer is mixed in the waste plastic mix concrete. The slump is prone to decreasing sharply with increasing waste plastic ratio. This reduction can be attributed to the fact that plastic particles have nonuniform shapes resulting in less fluidity. But, in spite of slump reduction, the waste plastic concrete mixtures have easy workability since plastic increases the flow of the concrete.

3.4. Compressive Strength. By increasing the waste plastic ratio, the compressive strength values of waste plastic concrete mixtures decrease at each curing age. This trend can be attributed to the decrease in adhesive strength between the surface of the waste plastic and the cement paste, as well as the particles size of the waste plastic increase. However, the compressive strength tends to increase by $5 \%$ when superplasticizer is added to the waste plastic mix concrete. The results of compressive strength test are also shown graphically in Figures 5 and 6 for comparative analysis. It is observed here that, with increasing amount of waste plastic, the rate of reduction in strength gets flatter and the maximum reduction is only about $15 \%$. It is interesting to note here that, when $20 \%$ waste plastic was partially replaced with fine aggregate, the compressive strength at 28 days was well below the strength of reference mix concrete. Therefore the variation was limited to only up to $15 \%$.

3.5. Flexural Strength. The flexural strength calculations are done as per IS: 516-1959. Figure 7 shows that the flexural strength of waste plastic mix concrete is prone to decrease with the increase of the waste plastic ratio in these mixtures. This trend can be attributed to the decrease in adhesive strength between the surface of waste plastic particles and the cement paste. However, the flexural strengths of the waste plastic concrete composites compared similarly with those of previous works $[12,14]$.

\section{Conclusions}

The reduced slump values of waste plastic concrete mixes show that it can be used only in situations that required low-degree workability. Such situations are numerous in civil engineering applications, namely, precast bricks, partition wall panels, canal linings, and so forth. However, the workability increases by about 10 to $15 \%$ when superplasticizer is added to the waste plastic mix concrete. The comprehensive strength decreases with increasing waste plastic ratios at 


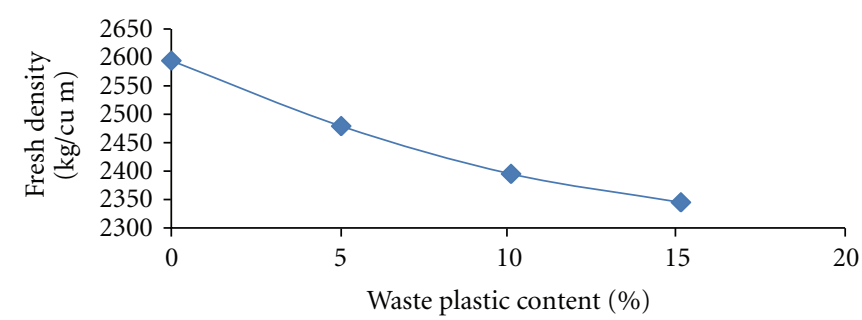

Figure 2: Graph for fresh density.

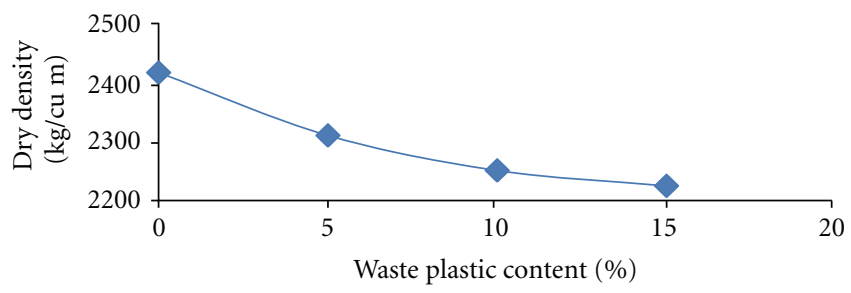

Figure 3: Dry density after 28 days.

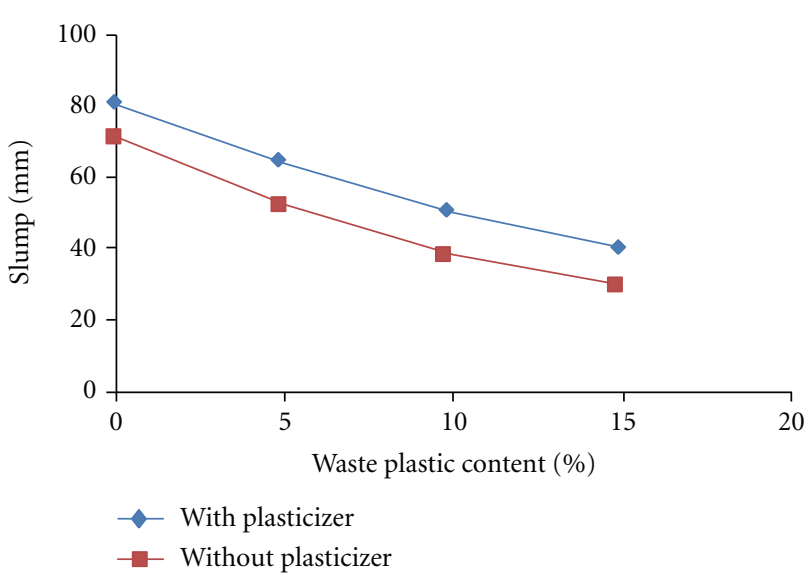

Figure 4: Slump of concrete mix with varying \% of waste plastic.

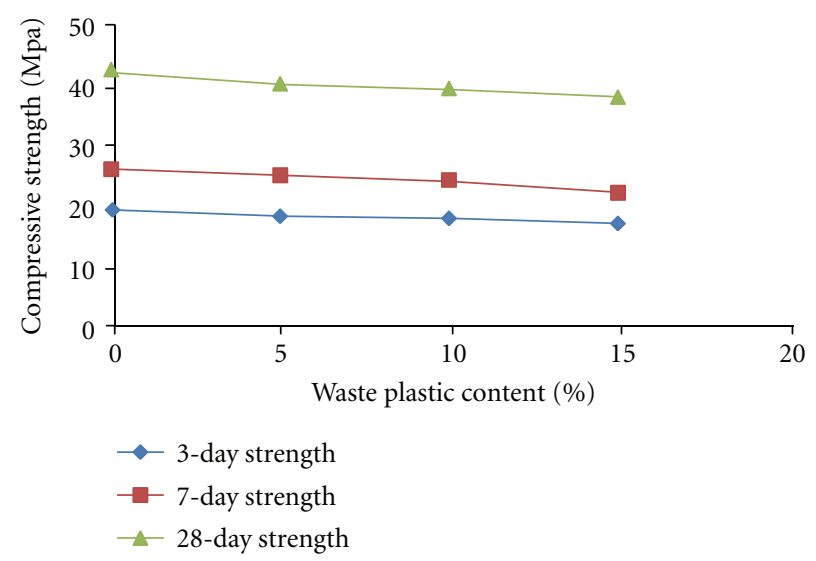

Figure 5: Compressive strength of concrete with varying $\%$ of plastic waste without superplasticizer.

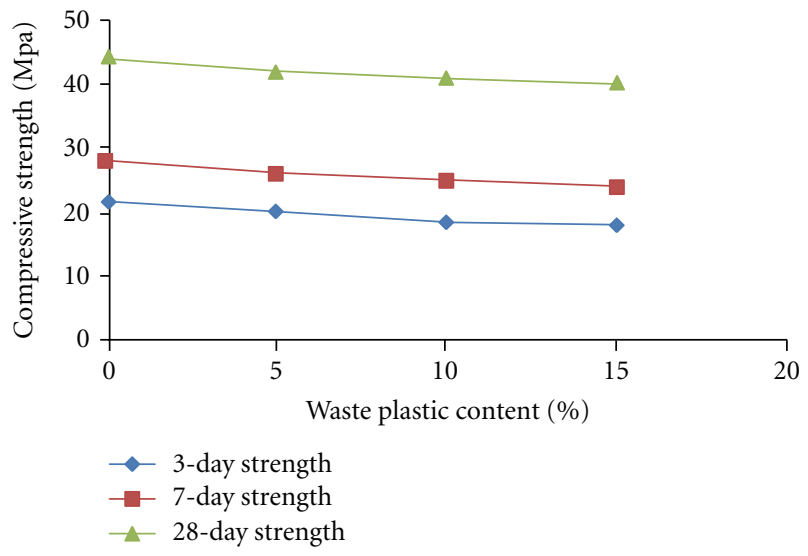

Figure 6: Compressive strength of concrete with varying \% of plastic waste with superplasticizer.

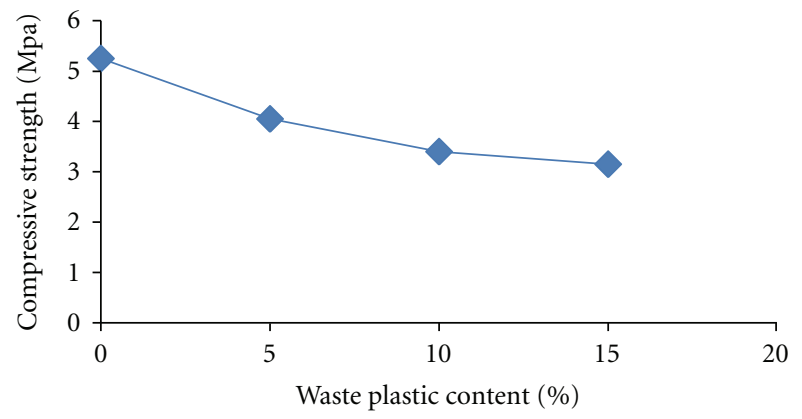

Figure 7: Flexural strength of concrete mix with varying \% of waste plastic.

all curing ages. This may be attributed to the decrease in the adhesive strength between the waste plastic and the cement paste. It seems that the bonding between the plastic particles and the cement paste is weak. Further, 
the compressive strength increases by about $5 \%$ after addition of superplasticizer to the mix. With increasing amount of waste plastic, the rate of reduction in strength gets flatter and the maximum reduction is only about $15 \%$ for all grades of concrete. Flexural strength of waste plastic mix concrete decreases with the increase in percentage of plastic waste. It was observed that the effect of plasticizer on flexural strength of concrete is irrelevant.

\section{References}

[1] CUR Report, "Fly ash as addition to concrete," Tech. Rep. 144, Centre for Civil Engineering Research and Codes, Gouda, The Netherlands, 1991.

[2] K. Sakai, H. Watanabe, M. Suzuki, and V. M. Malhotra, "Properties of granulated blast-furnace slag cement concrete," in Proceedings of the 4th International Conference Fly Ash, Silica Fume, Slag and Natural Pozzolans in Concrete, vol. 2, pp. 13671383, Detroit, Mich, USA, 1992.

[3] American Concrete Institute, "Ground granulated blastfurnace slag as a cementitious constituent in concrete," in ACI Manual of Concrete Practice, Part I: Materials and General properties of Concrete, p. 16, Detroit, Mich, USA, 1994.

[4] T. C. Holland and M. D. Luther, "Improving concrete durability with silica fume, in Concrete and Concrete Construction," in Proceedings of the International Symposium on Concrete and Concrete Construction, L. H. Tuthill, Ed., pp. 107-122, Detroit, Mich, USA, 1987.

[5] V. Corinaldesi, G. Moriconia, and T. R. Naikb, "Characterization of marble powder for its use in mortar and concrete," in Proceedings of the International Symposium on Sustainable Development of Cement and Concrete, Toronto, Canada, October 2005.

[6] Gupta et al., "Study of the use of plastic from municipal solid waste in concrete as a disposal technique," in QIP Short Term Training Program on "Emerging Technology For Environmental Management”, Department of Civil Engineering, New Delhi, India, 2006.

[7] H. Binici, H. Kaplan, and S. Yilmaz, "Influence of marble and limestone dusts as additives on some mechanical properties of concrete," Scientific Research \& Essay, vol. 2, no. 9, pp. 372379, 2007.

[8] M. Batayneh, I. Marie, and I. Asi, "Use of selected waste materials in concrete mixes," Waste Management, vol. 27, no. 12, pp. 1870-1876, 2007.

[9] K. S. Rebeiz, "Precast use of polymer concrete using unsaturated polyester resin based on recycled PET waste," Construction and Building Materials, vol. 10, no. 3, pp. 215-220, 1996.

[10] C. A. Sikalidis, A. A. Zabaniotou, and S. P. Famellos, "Utilisation of municipal solid wastes for mortar production," Resources, Conservation and Recycling, vol. 36, no. 2, pp. 155$167,2002$.

[11] Y. W. Choi, D. J. Moon, J. S. Chung, and S. K. Cho, "Effects of waste PET bottles aggregate on the properties of concrete," Cement and Concrete Research, vol. 35, no. 4, pp. 776-781, 2005.

[12] O. Y. Marzouk, R. M. Dheilly, and M. Queneudec, "Valorization of post-consumer waste plastic in cementitious concrete composites," Waste Management, vol. 27, no. 2, pp. 310-318, 2007.
[13] B. W. Jo, S. K. Park, and C. H. Kim, "Mechanical properties of polyester polymer concrete using recycled polyethylene terephthalate," ACI Structural Journal, vol. 103, no. 2, pp. 219225, 2006.

[14] L. Pezzi, P. De Luca, D. Vuono, F. Chiappetta, and A. Nastro, "Concrete products with waste's plastic material (bottle, glass, plate)," Materials Science Forum, vol. 514-516, no. 2, pp. 17531757, 2006. 

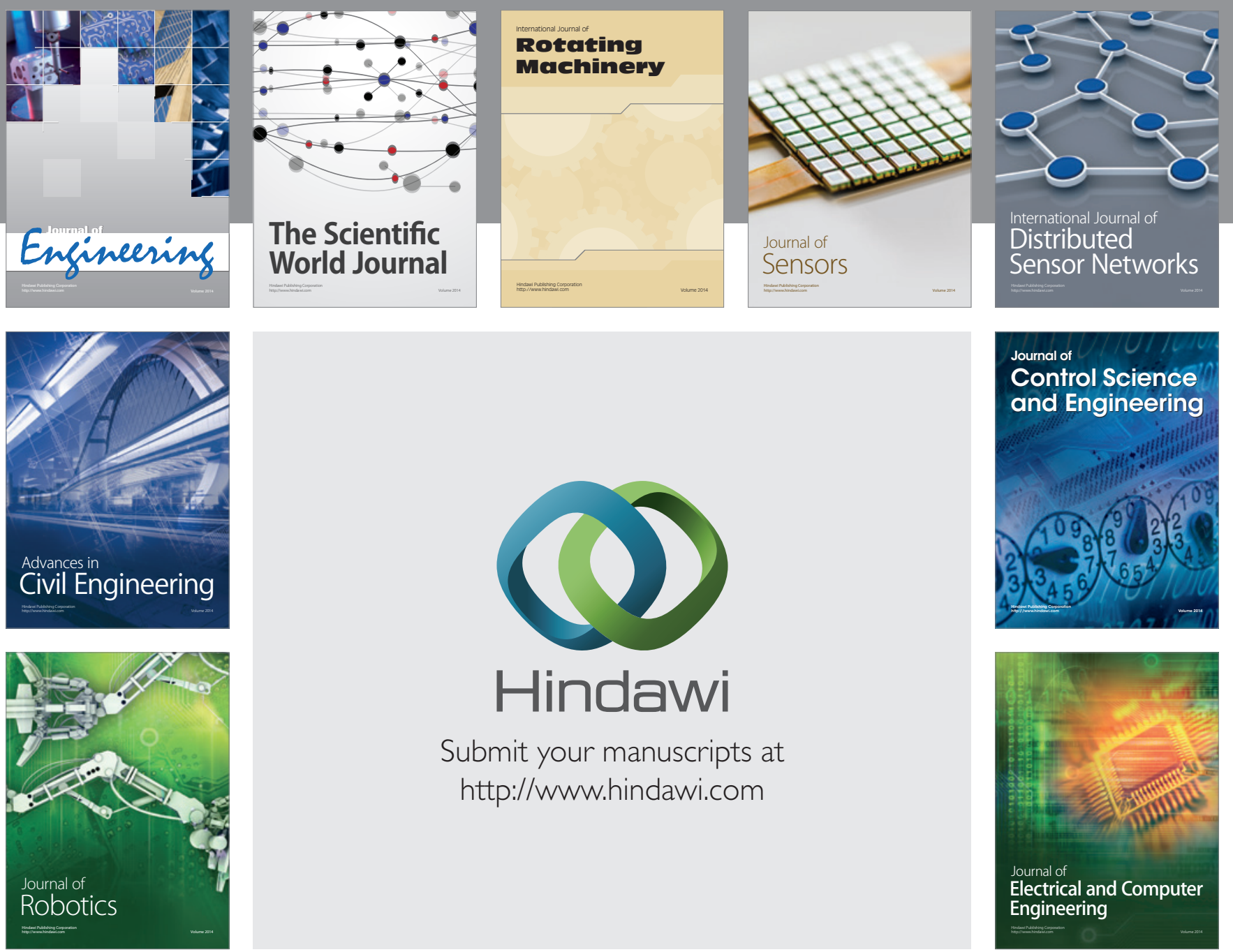

Submit your manuscripts at

http://www.hindawi.com
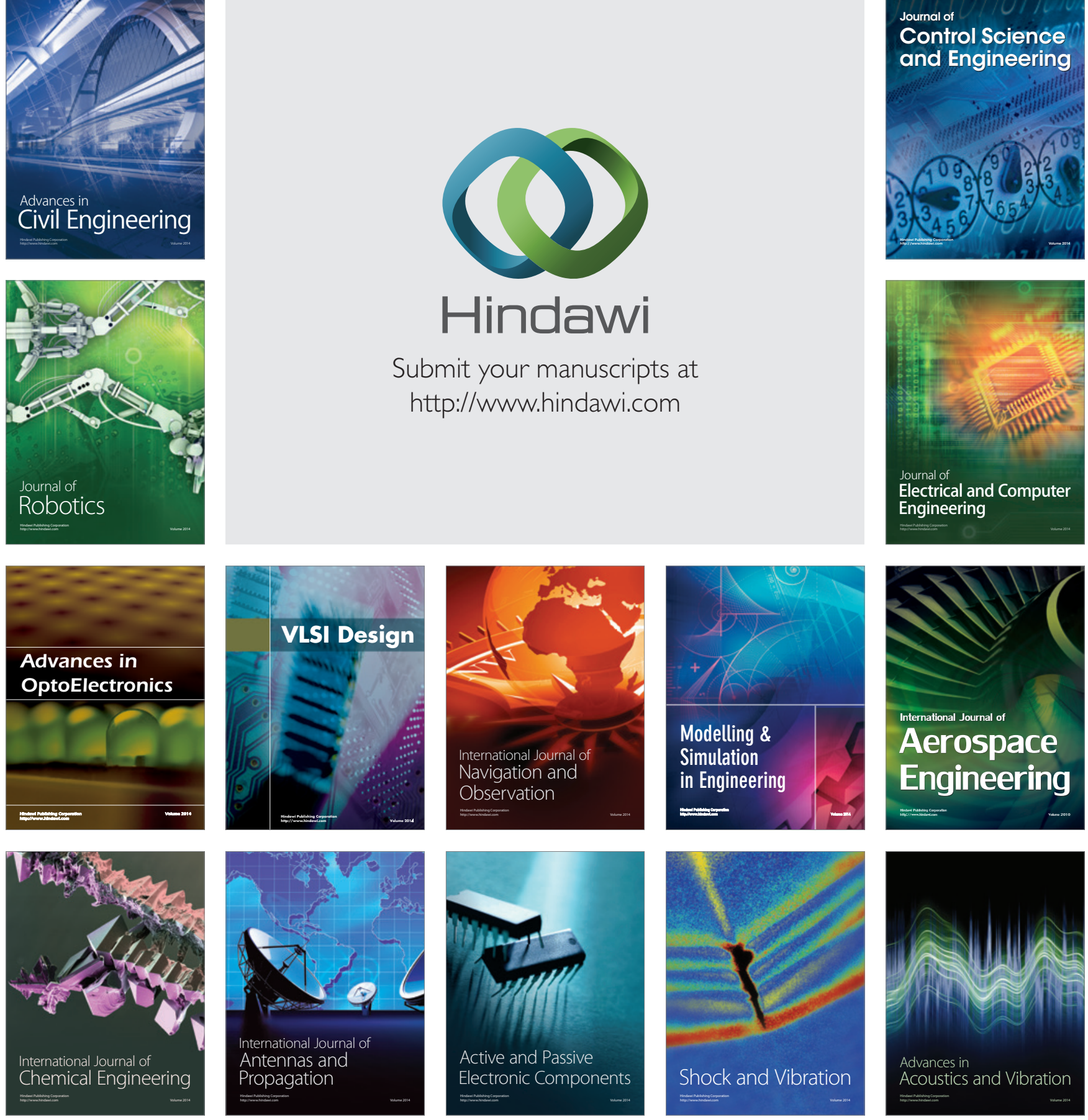